\title{
Inter-annual precipitation fluctuation shapes plant communities regardless of fertilization addition and mycorrhizal suppression in desert steppe
}

\author{
Xin Yang ${ }^{1}$, Jiayi Zang ${ }^{1}$, Jialin Feng ${ }^{1}$, and Yue Shen ${ }^{1}$ \\ ${ }^{1}$ Ningxia University
}

February 28, 2022

\begin{abstract}
Intensified inter-annual precipitation fluctuation has profoundly altered the structure and functioning of grassland ecosystems. However, it remains elusive how fertilisation and arbuscular mycorrhizal (AM) fungi affect plant communities under a variable precipitation regime. We tested the interactive effects of inter-annual precipitation fluctuation, nutrient addition (nitrogen, $\mathrm{N}$ and phosphorus, $\mathrm{P}$ ) and suppression of AM fungi on aboveground net primary productivity (ANPP) and the species composition of plant community of a desert steppe for two consecutive years (2019 and 2020). Our study demonstrated that inter-annual precipitation fluctuation had a greater impact on ANPP and the species composition of plant community than N and P addition and AM fungi, suggesting that the impacts of fertilisation and AM fungi varied by year and may be difficult to predict over time. In a normal year (2019), N and P inputs altered the ANPP and the species composition of plant community via enhancing the biomass and dominance of annual species but had few impacts on the same parameters in a dry year (2020). AM fungi had only a minimal effect on plant communities across the two years. P input alone slightly enhanced plant species richness and diversity. Our results indicate that plant community responses to nutrient enrichment and AM fungi could be changed by inter-annual precipitation fluctuation and that precipitation is a key factor affecting plant communities in desert steppe.
\end{abstract}

\section{INTRODUCTION}

Climate change may amplify inter-annual precipitation fluctuation in terrestrial ecosystems (Alan K. Knapp, Avolio, et al., 2017; Sloat et al., 2018; W. Zhang \& Zhou, 2019), and interactions between precipitation fluctuation and anthropogenic activities (e.g. overgrazing, land use change and fertilisation) could have significant impacts on grassland ecosystem structure and functioning (Ahlborn et al., 2021; Brambila, Chesnut, Prugh, \& Hallett, 2020; Cui et al., 2020a; Han et al., 2021; L. Huang et al., 2019). Arid and semi-arid grassland ecosystems generally experience high inter-annual precipitation variation (Carmona, Mason, Azcarate, \& Peco, 2015; Alan K. Knapp, Ciais, \& Smith, 2017; A. K. Knapp \& Smith, 2001; Kong et al., 2013) and anthropogenic activity-induced soil nutrient enrichment (Ma et al., 2020; Yahdjian, Gherardi, \& Sala, 2011). In grassland ecosystems, arbuscular mycorrhizal (AM) fungi can colonize over $80 \%$ of terrestrial plants, which can improves host plant elements absorption (Smith \& Read, 2008). However, much of our current understanding of plant community performances in desert steppe in relation to inter-annual precipitation fluctuation is based on the changes of plant productivity and diversity (Ahlborn et al., 2021; Han et al., 2021; Alan K. Knapp, Avolio, et al., 2017) and assessed independently of the effects of added nutrients and AM fungi (J. Huang et al., 2021; J. Huang et al., 2016; Qiao et al., 2019). As such, it is critical that we clarify plant community responses to the potential interactive impacts of multiple factors such as inter-annual fluctuation in precipitation, soil nutrient availability and AM fungi. Additionally, a reliable benchmark is needed to develop a robust understanding of arid grassland sensitivity using terrestrial ecosystem models (Püschel, Bitterlich, Rydlová, \& Jansa, 2021; Xin Yang, Shen, Badgery, Guo, \& Zhang, 2018). 
Precipitation in growing season is a vital driver affecting variation in ANPP and plant community composition in grasslands (Bai, Han, Wu, Chen, \& Li, 2004; Irisarri et al., 2016). However, plant communities can vary drastically in response to precipitation fluctuation (Hsu, Powell, \& Adler, 2012; Alan K. Knapp, Avolio, et al., 2017; Koerner, Collins, Blair, Knapp, \& Smith, 2014; Reichmann et al., 2018). For example, annual primary production is more sensitive to inter-annual fluctuation in precipitation in arid grassland than in humid grassland (Maurer, Hallmark, Brown, Sala, \& Collins, 2020). Furthermore, evidence from recent field studies shows that environmental factors (e.g. soil nutrient availability and soil microorganisms) may affect plant communities in response to inter-annual precipitation fluctuation (Felton, Slette, Smith, \& Knapp, 2020; J. Huang et al., 2016). Thus, our current konwledge of the responses of plant communities to inter-annual precipitation fluctuation may be impeded by a limited understanding of multiple factors.

Anthropogenic input of nitrogen $(\mathrm{N})$ and phosphorous $(\mathrm{P})$ can synergistically promote aboveground net primary productivity (ANPP), reduce plant species richness and change the dominance of plant species in nutrient-limited grasslands (Suding et al., 2005). The impacts of nutrients input on ANPP and plant diversity rely on the abundance and nutrient uptake strategy of plant species; $\mathrm{N}$ input favours the dominance of perennial grasses rather than other plant species (Avolio et al., 2014; Ma et al., 2020; Stevens et al., 2020). Nevertheless, $\mathrm{P}$ input alone promotes high abundance and shoot biomass in legumes because they have higher P demands than other plant species (Benner \& Vitousek, 2007). Thus, it is necessary to consider the nutrient responses of various plant species to effectively interpret how the addition of nutrients changes plant communities.

Nutrient supply to plants can also alter the structure and functioning of AM fungi via changing the exchange of carbon (C) and P (Johnson, Wilson, Wilson, Miller, \& Bowker, 2015; Kiers et al., 2011). Field studies found that $\mathrm{N}$ and/or P input could weaken the impacts of AM fungi on ANPP and plant species richness (G. W. Yang et al., 2014; T. Zhang \& Feng, 2021). In general, AM fungi promote ANPP when soil available P is limited and vice versa (Collins \& Foster, 2009; Johnson et al., 2015; G. W. Yang et al., 2014). In contrast, AM fungi have a neutral impact on ANPP when $\mathrm{N}$ is limited but reduce it when $\mathrm{N}$ is enriched (Jiang et al., 2018). Relatively high soil nutrient availability, especially high $\mathrm{P}$, can decrease belowground $\mathrm{C}$ allocation in plants, thus directly reducing C supply for AM fungi (Zheng et al., 2018) and changing this symbiotic relationship from mutualism to parasitism (Jiang et al., 2018; Johnson, 2010).

Desert steppe generally has low ANPP and plant diversity because of soil water and nutrients (N and P) are strangely limited (Alan K. Knapp, Ciais, et al., 2017). Precipitation in the growing season in the desert steppe in China varies drastically between years, ranging from 111.4 to $382.4 \mathrm{~mm}$ (Zhao et al., 2019). AM fungi can still benefit plant $\mathrm{N}$ and $\mathrm{P}$ nutrition in this water- and nutrient-limited conditions (Qiao et al., 2019). Thus, we conducted a two-year field study to evaluate the inter-annual response of ANPP and plant species composition to nutrient addition $(\mathrm{N}, \mathrm{P}$ and $\mathrm{N}+\mathrm{P}$ ) and $\mathrm{AM}$ fungi suppression in desert steppe. We examined the following three hypotheses: (1) inter-annual precipitation fluctuation alters ANPP and plant species composition response to $\mathrm{N}$ and $\mathrm{P}$ addition and AM fungal suppression; (2) the addition of nutrients enhances ANPP by changing the plant growth response in combination with AM fungi; and (3) inter-annual precipitation fluctuation changes the dominant species in a community regardless of nutrient addition and mycorrhizal suppression.

\section{MATERIALS AND METHODS}

\subsection{Study site}

This field study was carried out in a natural grassland in the Northwest China ( $\left.37^{\circ} 76 \mathrm{~N}, 107^{\circ} 28 \mathrm{E}\right)$. The annual average precipitation of this study site was $289.4 \mathrm{~mm}$ from 1980 to 2020, most of which fell between April and September (Fig. S1). The long-term (1980-2010) average annual temperature is $7.8{ }^{\circ} \mathrm{C}$. The soil type in this region is sandy loam and has a $\mathrm{pH}$ of 8.27 ; the soil available $\mathrm{N}$ is $4.48 \mathrm{mg} \mathrm{kg}^{-1}$, and soil available $\mathrm{P}$ is $1.87 \mathrm{mg} \mathrm{kg}^{-1}$. The study site is a Stipa brevifloradesert steppe. Stipa breviflora (Poaceae), a perennial $\mathrm{C}_{3}$ bunch grass, is a dominant species, in addition to plant species such as Agropyron mongolicum(Poaceae, $\mathrm{C}_{3}$ grass), Chenopodium aristatum (Chenopodiaceae, $\mathrm{C}_{4}$ forb) and Cleistogenes squarrosa (Poaceae, $\mathrm{C}_{4}$ grass). 
Stipa breviflora, A. mongolicumand C. squarrosa are considered to be mycorrhizal plants (Bao \& Yan, 2004; H. Tian, Gai, Zhang, Christie, \& Li, 2009; Xin Yang, Liu, Tian, \& Shen, 2021). In contrast, C. aristatum cannot be colonised by AM fungi and is considered a non-mycorrhizal plant (H. Tian et al., 2009).

\subsection{Experimental design}

Our field study was conducted in May 2019 in fenced grassland and had a complete randomised block design. This field experiment was conducted in five $2 \mathrm{~m}$ x $23 \mathrm{~m}$ blocks. We created 40 plots, each measuring $2.2 \mathrm{~m}$ x $2.2 \mathrm{~m}$, in each of these blocks, and then allocated one of eight different treatment regimens to each of the plots. The buffer zones around the plots and blocks measured $1 \mathrm{~m}$. The following treatments were combined in a cross factorial experiment: application of 0 or $10 \mathrm{~g} \mathrm{~N} \mathrm{~m}^{-2 *}$ year ${ }^{-1}\left(\mathrm{NH}_{4} \mathrm{NO}_{3}\right)$, application of 0 or $10 \mathrm{~g}$ $\mathrm{P} \mathrm{m}^{-2 *}$ year $^{-1}\left[\mathrm{Ca}\left(\mathrm{H}_{2} \mathrm{PO} 4\right)_{2}\right]$ and application of fungicide to suppress mycorrhizal fungi $[12 \mathrm{~g}$ benomyl $(50 \%$ active substance) in $10 \mathrm{~L}$ of deionized water per $\mathrm{m}^{2}$ ] or plain water. The levels of $\mathrm{N}$ and $\mathrm{P}$ added exceeded the natural deposition rates of these nutrients in East Asia (Cui et al., 2020b; H. Yang et al., 2012), but conformed to predictions of $\mathrm{N}$ and $\mathrm{P}$ deposition from land use change and atmosphere (Cui et al., 2020b). In the early summer months, $\mathrm{NH}_{4} \mathrm{NO}_{3}$ and $\mathrm{Ca}\left(\mathrm{H}_{2} \mathrm{PO} 4\right)_{2}$ were inputted by manual work and distributed after sunset (when soil moisture levels were higher). The mycorrhizal suppression plots were treated with fungicide twice per month in growing season, and the mycorrhizal plots were inputed through the same amount of plain water at the same time points. Benomyl was used as a fungicide because it can effectively reduce AM fungal colonisation and extra-radical biomass, but it has slightest side effects on host plants and other soil microorganisms in native grasslands (Jia, Walder, Wagg, \& Feng, 2021; Qiao et al., 2019; Xue Yang, Mariotte, Guo, Hautier, \& Zhang, 2021).

\section{3 ampling procedure}

Vegetation sampling was performed in two random quadrats $(0.5 \times 0.5 \mathrm{~m})$ in each experimental plot in midAugust 2019 and 2020. Plant species in each quadrat were identified and destructively clipped to measure shoot biomass. In 2019 and 2020, the quadrats were conducted at different sites in each plot to avoid resampling. Plant samples were weighed and recorded after over-drying at $65 \mathrm{deg} \mathrm{C}$ for $48 \mathrm{~h}$. The plant diversity (Shannon index, $H^{\prime}$ ') was measured for each plot (Yu et al., 2021).

Soil samples were botained randomly in the end of growing season (mid-August in 2019 and 2020). Three holes (soil depth: $10 \mathrm{~cm}$ ) were drilled from each plot, and the soil from these holes was mixed into one soil sample per plot $(\sim 200 \mathrm{~g})$. Each mixed soil sample was sieved via a soil mesh ( $2 \mathrm{~mm}$ bore diameter $)$ to take out plant roots and stones. Soil and plant root samples was stored in the laboratory.

\section{Sample analyses}

Soil available N and P may alter AM fungal impacts on plant fitness in native grassland (Johnson, 2010; G. Yang et al., 2016). Therefore, soil available $\mathrm{P}$ and inorganic $\mathrm{N}$ in each experimental plot were measured annually; soil available $\mathrm{P}$ was measured through the Olsen method (Belanger \& Rees, 2007), while soil inorganic $\mathrm{N}\left(\mathrm{NH}_{4}{ }^{+}-\mathrm{N}\right.$ and $\left.\mathrm{NO}_{3}{ }^{-}-\mathrm{N}\right)$ was determined by a flow injection autoanalyser (Flowsys; Ecotech, Germany). Mycorrhizal root colonisation was assessed using the method described by Trouvelot (1986)(Trouvelot, 1986). The extra-radical biomass of AM fungi was measured by soil neutral lipid fatty acid (NLFA) analysis (Andrino, Guggenberger, Sauheitl, Burkart, \& Boy, 2021; Cozzolino, Di Meo, Monda, Spaccini, \& Piccolo, 2016; Stevens et al., 2020).

\subsection{Statistical analyses}

To evaluate the impacts of inter-annual precipitation fluctuation and experimental treatments on plant, soil and AM fungal parameters, repeated measures analysis of variance (ANOVA) was used with N, P and fungicide application as between-subject factors, and year as a within-subject factor. In addition, three-way ANOVA (N, P and fungicide application) was used to test the impacts of experimental treatments on these parameters. Statistical analyses were conducted via SPSS software (version 21.0; IBM, Armonk, NY, USA).

To evaluate the direct and indirect impacts of the experimental treatments on ANPP, we performed struc- 
tural equation modelling (SEM) in Amos (version 18.0, IBM, USA). In our SEM model, we supposed that precipitation, $\mathrm{N}$ and $\mathrm{P}$ addition and AM fungi can impact ANPP both directly and indirectly by altering the aboveground biomass of main plant species. We examined the model's fitness using the $\chi^{2}$ test, root mean square error of approximation and Akaike information criterion. $\chi^{2}$ values and $P$-values $>0.05$ suggested that the covariance of the chosen data was no significantly differ with which we expected (Grace, 2006).

\section{RESULTS}

\subsection{Inter-annual precipitation fluctuation}

The precipitation amount in 2019 and 2020 was 323.1 and $205.2 \mathrm{~mm}$, respectively (Fig. S1). The precipitation amount in growing season (from April to September) in 2019 and 2020 was 272.6 and $176.3 \mathrm{~mm}$, respectively, and accounted for $84.4 \%$ of annual precipitation in 2019 and $85.91 \%$ of annual precipitation in 2020 (Fig. $\mathrm{S} 1)$. The precipitation amount in growing season in 2019 was higher than that in long-term (246.6 mm; 1980-2020 average), but that in 2020 was lesser than the long-term average (Fig. S1). Precipitation in the early stage of growing season (from April to July) in 2019 was much higher than that in 2020 (Fig. S1). However, precipitation in August in 2020 was higher than that in 2019 (Fig. S1).

\subsection{ANPP and the aboveground biomass of plant species}

Precipitation and $\mathrm{N}$ and $\mathrm{P}$ addition interactively altered ANPP over the two experimental years (Table 1). We found the significant positive interaction between ANPP and N and P combined only in 2019 (the normal year); P alone enhanced ANPP by $63.95 \%$, but N + P addition together increased it by $199.40 \%$ (Fig. 1a). However, in the dry year (2020), P input alone increased ANPP by $139.08 \%$ (Fig. 1b). Mycorrhizal suppression had only a minimal effect on ANPP in both 2019 and 2020 (Fig. 1a and b, $p>0.05$ ).

Meanwhile, the shoot biomass of plant species exhibited a much higher degree of inter-annual fluctuation than ANPP (Table 1). In the normal year (2019), mycorrhizal suppression reduced the aboveground biomass ofS. breviflora by $63.11 \%$ wherear enhanced it by $42.19 \%$ and $179.63 \%$, respectively, in $\mathrm{N}+\mathrm{P}$ addition plots (Table 1; Fig. 2a, $\mathrm{F} \times \mathrm{N} \times \mathrm{P}: F_{1,28}=8.79, p<0.01$ ); however, there were no significant interactions between these factors during the dry year (Fig. 2b). The aboveground biomass of C. squarrosa and $C$. aristatum was higher in the normal year (2019) than that in the dry year (2020), but the opposite was true for A. mongolicum (Fig. 2c-h). Importantly, in the dry year (2020), the aboveground biomass of C. aristatum was drastically decreased (Fig. 2h). Across all years, $\mathrm{P}$ input alone significantly enhanced the aboveground biomass of A. mongolicum, C. aristatum and C. squarrosa (Fig. $2 \mathrm{c}-\mathrm{h}$, Table 1, P: $F_{1,28}=27.83, p<0.01$; $F_{1,28}=8.27, p<0.01 ; F_{1,28}=54.11, p<0.01$, respectively $)$.

The best SEM model explained $89 \%$ of the variation in ANPP (Fig. $3 ; \chi^{2}=15.167, p=0.232$ ). Precipitation and $\mathrm{N}$ and $\mathrm{P}$ input explained $47 \%$ of the deviation in the aboveground biomass of C. aristatum ; AM fungi had a limited impact on this parameter (Fig. 3). The aboveground biomass of C. aristatum (standardised effect size: 0.42), A. mongolicum (standardised effect size: 0.51), S. breviflora (standardised effect size: 0.30) and C. squarrosa (standardised effect size: 0.11) contributed positively to ANPP (Fig. 3).

\subsection{Plant community composition}

Inter-annual precipitation fluctuation strongly shaped plant community composition through altering the relative aboveground biomass of main plant species (Table S2; Y: all $p<0.01$ ). In particular, the relative plot biomass of C. aristatum was drastically decreased in the dry year (Fig. 4a-d). Mycorrhizal suppression had no significant impact on plant community composition across the two experimental years (Table S3; all $p>0.05)$. $\mathrm{P}$ input alone greatly enhanced the relative aboveground biomass of C. aristatum and $A$. mongolicum (Table S2, Fig. 3). Inter-annual precipitation fluctuation strongly changed species richness and plant Shannon index (Table S3; Y: all $p<0.01$ ), which was higher in 2019 than in 2020 (Fig. S2). P input alone significantly increased plant species richness from 2019 to 2020 (Fig. S2a and b; $F_{1,28}=21.06, p<$ $0.01 ; F_{1,28}=22.50, p<0.01$, respectively), but $\mathrm{N}$ addition alone and fungicide application did not change it (Table S3, all $p>0.05$ ). 


\subsection{AM fungi and soil properties}

Fungicide (benomyl) addition significantly reduced mycorrhizal root colonisation across all plots from 2019 to 2020 (Fig. 4). Furthermore, P input alone significantly reduced mycorrhizal root colonisation in comparison with the control over two years (Fig. 5). Besides, we found that fungicide (benomyl) addition had minimal influence on soil available $\mathrm{P}$ and inorganic $\mathrm{N}$ in either 2019 or 2020 in our study (Fig. S2; all $p>0.05$ ). In 2020, N input alone enhanced soil inorganic N by $121.17 \%$ compared with control plots (Fig. S3a and b; $F$ $1,28=93.44, p<0.01)$. Moreover, $\mathrm{P}$ input alone enhanced soil available $\mathrm{P}$ in the soil by over 10 times $(2019)$ and 14 times (2020) relative to control plots (Fig. S3c and d; $F_{1,28}=81.26, p<0.01, F_{1,40}=191.68, p$ $<0.01$, respectively). Mycorrhizal suppression and $\mathrm{P}$ input alone greatly decreased AM fungal neutral lipid fatty acid concentrations in 2019 and 2020 (Fig. S4a and b, Table S4) but did not change those of other microbial groups (Table S4, all $p>0.05$ ).

\section{DISCUSSION}

\subsection{ANPP}

As we expected, the response of ANPP to both $\mathrm{N}$ and $\mathrm{P}$ inputs varied between years, possibly because of differences in precipitation. The amount of precipitation is the main limiting factor constraining plant productivity in arid grassland (Bai et al., 2004; Irisarri et al., 2016; A. K. Knapp \& Smith, 2001; Ma et al., 2020). Plant communities are sensitive to fluctuation in precipitation and $\mathrm{N}$ availability in dryland ecosystems (Ma et al., 2020). Furthermore, increased soil moisture can diminish the negative impacts of $\mathrm{N}$ input on plant communities (Ma et al., 2020). In accordance with the co-limitation theory (Harpole et al., 2011), N and P inputs can synergistically increase ANPP only when water is not limited, as was the case in the present study in 2019, which was a normal year in terms of precipitation. Consistent with our results, nutrient addition only enhanced ANPP when there was sufficient water in the desert steppe (Ma et al., 2020; Qiao et al., 2019).

\subsection{Plant community composition}

Nutrient input can considerably alter plant species composition in native grassland, and favour the dominance of perennial grasses rather than other plant species (Avolio et al., 2014; Q. Tian et al., 2016). Supporting our first hypothesis, the response of plant species composition to both $\mathrm{N}$ and $\mathrm{P}$ inputs and mycorrhizal suppression in the present study was year-dependent. Specifically, N + P addition drastically favoured the dominance from $S$. breviflora over $C$. aristatum, but only in 2019 (a normal year). However, in the dry year (2020), $C$. aristatum had a lower relative shoot biomass in the plant community compared to that in the normal year (2019). According to the competitive exclusion principle (Gause, 1934), a dominant annual species $(C$. aristatum in this case) can quickly gain dominance and overtake sub-dominant species in plant communities in arid grassland when sufficient soil water and nutrients are present (Wang et al., 2014).

We also found that $\mathrm{P}$ input alone altered plant richness and diversity in both years, perhaps because $\mathrm{P}$ addition improved the dominance of sub-dominant species (e.g. A. mongolicum and C. aristatum ). Further, $\mathrm{N}$ input alone had a weak impact on the dominance of common species, which is also in accordance with findings of earlier field and greenhouse studies (G. Yang et al., 2016; Xin Yang et al., 2021). However, Avolio et al. (2004) found that $\mathrm{N}$ addition alone could contribute to the almost all variance in plant community composition in tall grass prairies. Observed differences among the influences of both $\mathrm{N}$ and $\mathrm{P}$ inputs may relate to the specific properties of grassland types and study durations (Crowther et al., 2019; Song et al., 2019).

\subsection{Individual species}

Soil available nutrient enrichment can benefit the competitive ability of perennial grasses over other plant species (DeMalach \& Kadmon, 2017). However, our results indicate that, in the normal year (2019), N and/or P input effectively enhanced the aboveground biomass of $C$. aristatum than other dominant species. C. aristatum is generally viewed as a non-mycorrhizal plant in grassland ecosystems (H. Tian et al., 2009). Besieds, a meta-analysis also found that annual plant species were more able to rapidly absorb water and 
nutrients compared with other plant species (Lin, McCormack, \& Guo, 2015). C. aristatum has a shallow root system and can efficiently utilise resource that are distributed in the upper layers of soils, especially in arid grassland ecosystems (Yan et al., 2015). These characteristics may be attributed to the pronounced impacts of both $\mathrm{N}$ and $\mathrm{P}$ inputs on the aboveground biomass of C. aristatum in 2019.

\subsection{AM fungi and soil properties}

$\mathrm{P}$ input alone reduced mycorrhizal root colonisation at the plant community level. Furthermore, $\mathrm{P}$ input alone and $\mathrm{N}+\mathrm{P}$ addition together suppressed AM fungal colonisation. Our results are in accordance with other field studies, in which high soil $\mathrm{P}$ availability usually decreased mycorrhizal root colonisation and the extra-radical biomass of AM fungi (Avolio et al., 2014; G. Yang et al., 2016; G. W. Yang et al., 2014). The potential mechanism underlying these observations may be that relative high soil $\mathrm{P}$ availability generally decreases belowground C allocation, directly reducing C supply for AM fungi (Kiers et al., 2011).

Soil available P and inorganic N may alter the response of ANPP and plant diversity to AM fungi (Johnson et al., 2015; G. Yang et al., 2016). Our results indicated that both $\mathrm{N}$ and P inputs effectively enhanced the amount of soil available $\mathrm{P}$ and inorganic $\mathrm{N}$ regardless of inter-annual precipitation fluctuation. Our results are accordance with those found by Avolio et al. (2014) and Jiang et al. (2018). In our study, soil available $\mathrm{P}$ was higher in $\mathrm{P}$ alone and $\mathrm{N}+\mathrm{P}$ plots than that in controls, and presumably reduced mycorrhizal root colonisation. Changes in plant-available $\mathrm{N}$ observed in our study were less than the changes in plantavailable P, especially in 2019 (normal year). This may be attributable to the nutrient absorption ability of $C$. aristatum (a fast-growing annual forb), which can absorb plant-available $\mathrm{N}$ very effectively, leading to soil N depletion (Ehleringer, Schwinning, \& Gebauer, 2000).

Fungicide (benomyl) addition in contrasting precipitation conditions considerably suppressed mycorrhizal root colonisation. A growing number of field studies indicated that fungicide (benomyl) input may promote ANPP by enhancing soil available N (Chen \& Edwards, 2001; G. W. Yang et al., 2014). Nevertheless, the current study found that fungicide (benomyl) addition did not affect soil inorganic N, which is in agreement with a field study by Qiao et al. (2019).

\section{CONCLUSIONS}

In summary, our findings indicate that inter-annual precipitation fluctuation, rather than nutrient addition or AM fungal suppression, determines ANPP and plant species composition in desert steppe in the Northwest China. Furthermore, we also found that annual plant species in plant communities are more sensitive to precipitation than are other plant species, particularly in dry years. Therefore, we recommend that interactions among annual precipitation, fertilisation and AM fungi be incorporated into grassland management models when evaluating desert steppe ecosystem responses. Finally, our study indicate that the responses of plant communities in arid grassland to soil nutrient enrichment and symbiotic fungi vary over time. Unfortunately, our study was carried out across only two growing seasons with contrasting precipitation patterns, which limits our ability to understand plant community dynamics under various rainfall scenarios in the long term. Therefore, further studies are obliged to examine whether the responses of plant communities to nutrients input and AM fungi are consistent over longer periods.

\section{ACKNOWLEDGEMENTS}

We are grateful to the Yanchi field station of Ningxia University for supplying the research sites. This study was financial supported by the Agricultural Science and Technology Independent Innovation Funds of Ningxia Hui Autonomous Region (NGSB-2021-14-06) and Ningxia higher education institutions first-class discipline construction project (NXYLXK2017A01).

\section{CONFLICT OF INTEREST}

None declared

\section{AUTHORS' CONTRIBUTION}


J. Z. and J. F. contributed to conduct experiment, sample collection and data acquisition; X. Y. and Y. S. analyzed data and wrote the paper.

\section{DATA AVAILABILITY STATEMENT}

Rare data are available on Zenodo under https://doi.org/10.5281/zenodo.5509308

\section{REFERENCES}

Ahlborn, J., Wesche, K., Lang, B., Oyunbileg, M., Oyuntsetseg, B., Römermann, C., . . . von Wehrden, H. (2021). Interactions between species richness, herbivory and precipitation affect standing biomass in Mongolian rangelands.Applied Vegetation Science, 24(2), e12581. doi:https://doi.org/10.1111/avsc.12581

Andrino, A., Guggenberger, G., Sauheitl, L., Burkart, S., \& Boy, J. (2021). Carbon investment into mobilization of mineral and organic phosphorus by arbuscular mycorrhiza.Biology and Fertility of Soils, 57(1), 47-64. doi:10.1007/s00374-020-01505-5

Avolio, M. L., Koerner, S. E., La Pierre, K. J., Wilcox, K. R., Wilson, G. W. T., Smith, M. D., \& Collins, S. L. (2014). Changes in plant community composition, not diversity, during a decade of nitrogen and phosphorus additions drive above-ground productivity in a tallgrass prairie. Journal of Ecology, 102(6), 1649-1660. doi:10.1111/1365-2745.12312

Bélanger, N., \& Rees, K. C. J. V. (2007). Soil Sampling and Methods of Analysis. Second Edition.Crc Press, 15-24.

Bai, Y., Han, X., Wu, J., Chen, Z., \& Li, L. (2004). Ecosystem stability and compensatory effects in the Inner Mongolia grassland. Nature, 431 (7005), 181-184.

Bao, Y., \& Yan, W. (2004). Arbuscular mycorrhizae and their structural types on common plants in grasslands of mid-western Inner Mongolia. Biodiversity Science, 12(5), 501-508.

Benner, J. W., \& Vitousek, P. M. (2007). Development of a diverse epiphyte community in response to phosphorus fertilization. Ecology Letters, 10(7), 628-636. doi:10.1111/j.14610248.2007.01054.x

Brambila, A., Chesnut, J. W., Prugh, L. R., \& Hallett, L. M. (2020). Herbivory enhances the effect of environmental variability on plant community composition and beta diversity. Journal of Vegetation Science, 31(5), 744-754. doi:https://doi.org/10.1111/jvs.12862

Carmona, C. P., Mason, N. W. H., Azcarate, F. M., \& Peco, B. (2015). Inter-annual fluctuations in rainfall shift the functional structure of Mediterranean grasslands across gradients of productivity and disturbance. Journal of Vegetation Science, 26(3), 538-551. doi: $10.1111 /$ jvs.12260

Chen, S. K., \& Edwards, C. A. (2001). A microcosm approach to assess the effects of fungicides on soil ecological processes and plant growth: comparisons of two soil types. Soil Biology $\mathcal{G}^{3}$ Biochemistry, 33(14), 1981-1991. doi:10.1016/s0038-0717(01)00132-8

Collins, C. D., \& Foster, B. L. (2009). Community-level consequences of mycorrhizae depend on phosphorus availability. Ecology, 90(9), 2567-2576. doi:10.1890/08-1560.1

Cozzolino, V., Di Meo, V., Monda, H., Spaccini, R., \& Piccolo, A. (2016). The molecular characteristics of compost affect plant growth, arbuscular mycorrhizal fungi, and soil microbial community composition. Biology and Fertility of Soils, 52(1), 15-29. doi:10.1007/s00374-0151046-8

Crowther, T. W., Riggs, C., Lind, E. M., Borer, E. T., Seabloom, E. W., Hobbie, S. E., . . . Routh, D. (2019). Sensitivity of global soil carbon stocks to combined nutrient enrichment. 
Ecology Letters, 22(6), 936-945. doi:10.1111/ele.13258

Cui, H., Sun, W., Delgado-Baquerizo, M., Song, W., Ma, J.-Y., Wang, K., \& Ling, X. (2020a). The effects of mowing and multi-level $\mathrm{N}$ fertilization on soil bacterial and fungal communities in a semiarid grassland are year-dependent. Soil Biology and Biochemistry, 151, 108040. doi:https://doi.org/10.1016/j.soilbio.2020.108040

Cui, H., Sun, W., Delgado-Baquerizo, M., Song, W., Ma, J.-Y., Wang, K., \& Ling, X. (2020b). Phosphorus addition regulates the responses of soil multifunctionality to nitrogen over-fertilization in a temperate grassland. Plant and Soil. doi:10.1007/s11104-020-04620-2

DeMalach, N., \& Kadmon, R. (2017). Light competition explains diversity decline better than niche dimensionality. Functional Ecology, 31 (9), 1834-1838. doi:doi:10.1111/1365-2435.12841

Ehleringer, J. R., Schwinning, S., \& Gebauer, R. (2000). Water use in arid land ecosystems. Physiological Plant Ecology, 347-365.

Felton, A. J., Slette, I. J., Smith, M. D., \& Knapp, A. K. (2020). Precipitation amount and event size interact to reduce ecosystem functioning during dry years in a mesic grassland. Global Change Biology, 26(2), 658-668. doi:https://doi.org/10.1111/gcb.14789

Gause, G. F. (1934). Experimental analysis of Vito Volterra's mathematical theory of the struggle for existence. Science, $79(2036), 16-17$. doi:10.1126/science.79.2036.16-a

Grace, J. B. (2006).Structural equation modeling and natural systems. Cambridge, UK: Cambridge University Press.

Han, J., Chen, J., Shi, W., Song, J., Hui, D., Ru, J., \& Wan, S. (2021). Asymmetric responses of resource use efficiency to previous-year precipitation in a semi-arid grassland. Functional Ecology, 35(3), 807-814. doi:https://doi.org/10.1111/1365-2435.13750

Harpole, W. S., Ngai, J. T., Cleland, E. E., Seabloom, E. W., Borer, E. T., Bracken, M. E. S., . . S Smith, J. E. (2011). Nutrient co-limitation of primary producer communities. Ecology Letters, 14(9), 852-862. doi:https://doi.org/10.1111/j.1461-0248.2011.01651.x

Hsu, J. S., Powell, J., \& Adler, P. B. (2012). Sensitivity of mean annual primary production to precipitation. Global Change Biology, $18(7)$, 2246-2255. doi:https://doi.org/10.1111/j.13652486.2012.02687.x

Huang, J., Xu, Y., Yu, H., Zhu, W., Wang, P., Wang, B., \& Na, X. (2021). Soil prokaryotic community shows no response to 2 years of simulated nitrogen deposition in an arid ecosystem in northwestern China. Environmental Microbiology, 23(2), 1222-1237. doi:https://doi.org/10.1111/1462-2920.15364

Huang, J., Yu, H., Lin, H., Zhang, Y., Searle, E. B., \& Yuan, Z. (2016). Phosphorus amendment mitigates nitrogen addition-induced phosphorus limitation in two plant species in a desert steppe, China. Plant and Soil, 399(1-2), 221-232. doi:10.1007/s11104-015-2649-4

Huang, L., Wang, D., Yao, L., Li, X., Wang, D., Du, Q., . . . Guo, Y. (2019). Primary limitation on vegetation productivity shifts from precipitation in dry years to nitrogen in wet years in a degraded arid steppe of Inner Mongolia, northern China. Journal of Soils and Sediments, $19(2)$, 544-556. doi:10.1007/s11368-018-2070-8

Irisarri, J. G. N., Derner, J. D., Porensky, L. M., Augustine, D. J., Reeves, J. L., \& Mueller, K. E. (2016). Grazing intensity differentially regulates ANPP response to precipitation in North American semiarid grasslands. Ecological Applications, 26(5), 1370-1380. doi:10.1890/15-1332

Jia, Y., Walder, F., Wagg, C., \& Feng, G. (2021). Mycorrhizal fungi maintain plant community 
stability by mitigating the negative effects of nitrogen deposition on subordinate species in Central Asia. Journal of Vegetation Science, 32(1), e12944. doi:https://doi.org/10.1111/jvs.12944

Jiang, S., Liu, Y., Luo, J., Qin, M., Johnson, N. C., Opik, M., . . . Feng, H. (2018). Dynamics of arbuscular mycorrhizal fungal community structure and functioning along a nitrogen enrichment gradient in an alpine meadow ecosystem. New Phytologist, 220(4), 1222-1235. doi:10.1111/nph.15112

Johnson, N. C. (2010). Resource stoichiometry elucidates the structure and function of arbuscular mycorrhizas across scales. New Phytologist, 185(3), 631-647. doi:10.1111/j.14698137.2009.03110.x

Johnson, N. C., Wilson, G. W. T., Wilson, J. A., Miller, R. M., \& Bowker, M. A. (2015). Mycorrhizal phenotypes and the Law of the Minimum. New Phytologist, 205(4), 1473-1484. doi:10.1111/nph.13172

Kiers, E. T., Duhamel, M., Beesetty, Y., Mensah, J. A., Franken, O., Verbruggen, E., . . . Bucking, H. (2011). Reciprocal Rewards Stabilize Cooperation in the Mycorrhizal Symbiosis. Science, 333(6044), 880-882. doi:10.1126/science.1208473

Knapp, A. K., Avolio, M. L., Beier, C., Carroll, C. J. W., Collins, S. L., Dukes, J. S., . . - Smith, M. D. (2017). Pushing precipitation to the extremes in distributed experiments: recommendations for simulating wet and dry years. Global Change Biology, 23(5), 1774-1782. doi:10.1111/gcb.13504

Knapp, A. K., Ciais, P., \& Smith, M. D. (2017). Reconciling inconsistencies in precipitationproductivity relationships: implications for climate change. New Phytologist, 214(1), 41-47. doi:10.1111/nph.14381

Knapp, A. K., \& Smith, M. D. (2001). Variation among biomes in temporal dynamics of aboveground primary production. Science (New York, N.Y.), 291 (5503), 481-484. doi:10.1126/science.291.5503.481

Koerner, S. E., Collins, S. L., Blair, J. M., Knapp, A. K., \& Smith, M. D. (2014). Rainfall variability has minimal effects on grassland recovery from repeated grazing. Journal of Vegetation Science, 25(1), 36-44. doi:10.1111/jvs.12065

Kong, D. L., Lu, X. T., Jiang, L. L., Wu, H. F., Miao, Y., \& Kardol, P. (2013). Extreme rainfall events can alter inter-annual biomass responses to water and $\mathrm{N}$ enrichment. Biogeosciences, 10(12), 8129-8138. doi:10.5194/bg-10-8129-2013

Lin, G., McCormack, M. L., \& Guo, D. (2015). Arbuscular mycorrhizal fungal effects on plant competition and community structure. Journal of Ecology, 103(5), 1224-1232. doi:10.1111/1365-2745.12429

Ma, Q., Liu, X., Li, Y., Li, L., Yu, H., Qi, M., . . . Xu, Z. (2020). Nitrogen deposition magnifies the sensitivity of desert steppe plant communities to large changes in precipitation. Journal of Ecology, 108(2), 598-610. doi:https://doi.org/10.1111/1365-2745.13264

Maurer, G. E., Hallmark, A. J., Brown, R. F., Sala, O. E., \& Collins, S. L. (2020). Sensitivity of primary production to precipitation across the United States.Ecology Letters, 23(3), 527-536. doi:https://doi.org/10.1111/ele.13455

Puschel, D., Bitterlich, M., Rydlova, J., \& Jansa, J. (2021). Drought accentuates the role of mycorrhiza in phosphorus uptake. Soil Biology and Biochemistry, 108243. doi:https://doi.org/10.1016/j.soilbio.2021.108243 
Qiao, Y., Bai, Y., Zhang, Y., She, W., Lai, Z., \& Qin, S. (2019). Arbuscular mycorrhizal fungi shape the adaptive strategy of plants by mediating nutrient acquisition in a shrub-dominated community in the Mu Us Desert. Plant and Soil, 443(1), 549-564. doi:10.1007/s11104-01904253-0

Reichmann, L. G., Collins, H. P., Jin, V. L., Johnson, M.-V. V., Kiniry, J. R., Mitchell, R. B., . . Fay, P. A. (2018). Inter-Annual Precipitation Variability Decreases Switchgrass Productivity from Arid to Mesic Environments.BioEnergy Research, 11(3), 614-622. doi:10.1007/s12155-018-9922-3

Sloat, L. L., Gerber, J. S., Samberg, L. H., Smith, W. K., Herrero, M., Ferreira, L. G., . . - West, P. C. (2018). Increasing importance of precipitation variability on global livestock grazing lands. Nature Climate Change, 8(3), 214-218. doi:10.1038/s41558-018-0081-5

Smith, S. E., \& Read, D. J. (2008). Mycorrhizal Symbiosis ( $3^{\text {th }}$ ed ed.). New York: Elsevier.

Song, J., Wan, S., Piao, S., Knapp, A. K., Classen, A. T., Vicca, S., . . . Zheng, M. (2019). A meta-analysis of 1,119 manipulative experiments on terrestrial carbon-cycling responses to global change. Nature Ecology \& Evolution. doi:10.1038/s41559-019-0958-3

Stevens, B. M., Propster, J. R., Opik, M., Wilson, G. W. T., Alloway, S. L., Mayemba, E., \& Johnson, N. C. (2020). Arbuscular mycorrhizal fungi in roots and soil respond differently to biotic and abiotic factors in the Serengeti.Mycorrhiza, 30(1), 79-95. doi:10.1007/s00572-02000931-5

Suding, K. N., Collins, S. L., Gough, L., Clark, C., Cleland, E. E., Gross, K. L., . . . Pennings, S. (2005). Functional- and abundance-based mechanisms explain diversity loss due to $\mathrm{N}$ fertilization. Proceedings of the National Academy of Sciences of the United States of America, 102(12), 4387-4392. doi:10.1073/pnas.0408648102

Tian, H., Gai, J. P., Zhang, J. L., Christie, P., \& Li, X. L. (2009). Arbuscular mycorrhizal fungi associated with wild forage plants in typical steppe of eastern Inner Mongolia. European Journal of Soil Biology, 45(4), 321-327.

Tian, Q., Liu, N., Bai, W., Li, L., Chen, J., Reich, P. B., . . . Zhang, W.-H. (2016). A novel soil manganese mechanism drives plant species loss with increased nitrogen deposition in a temperate steppe. Ecology, 97(1), 65-74. doi:10.1890/15-0917.1

Trouvelot, A. (1986).Mesure du taux de mycorhization VA d'un systeme radiculaire. Recherche de methodes d'estimation ayant une significantion fonctionnelle. Paper presented at the Physiological and Genetical Aspects of Mycorrhizae, Paris, INRA.

Wang, Z., Zhang, Q., Xin, X., Ding, Y., Hou, X., Sarula, . . . Liu, Z. (2014). Response of the annual biomass production of a typical steppe plant community to precipitation fluctuations. The Rangeland Journal, 36(6), 527-534. doi:https://doi.org/10.1071/RJ14065

Yahdjian, L., Gherardi, L., \& Sala, O. E. (2011). Nitrogen limitation in arid-subhumid ecosystems: A meta-analysis of fertilization studies. Journal of Arid Environments, 75 (8), 675-680. doi:https://doi.org/10.1016/j.jaridenv.2011.03.003

Yan, H., Liang, C., Li, Z., Liu, Z., Miao, B., He, C., \& Sheng, L. (2015). Impact of Precipitation Patterns on Biomass and Species Richness of Annuals in a Dry Steppe.PLOS ONE, 10(4), e0125300. doi:10.1371/journal.pone.0125300

Yang, G., Yang, X., Zhang, W., Wei, Y., Ge, G., Lu, W., . . . Zhang, Y. (2016). Arbuscular mycorrhizal fungi affect plant community structure under various nutrient conditions and stabilize the community productivity.Oikos, 125(4), 576-585. doi:10.1111/oik.02351 
Yang, G. W., Liu, N., Lu, W. J., Wang, S., Kan, H. M., Zhang, Y. J., . . . Chen, Y. L. (2014). The interaction between arbuscular mycorrhizal fungi and soil phosphorus availability influences plant community productivity and ecosystem stability. Journal of Ecology, 102(4), 1072-1082. doi:10.1111/1365-2745.12249

Yang, H., Jiang, L., Li, L., Li, A., Wu, M., \& Wan, S. (2012). Diversity-dependent stability under mowing and nutrient addition: evidence from a 7-year grassland experiment. Ecology Letters, 15(6), 619-626. doi:10.1111/j.1461-0248.2012.01778.x

Yang, X., Liu, Y., Tian, H., \& Shen, Y. (2021). Short-term nitrogen and phosphorus additions rather than mycorrhizal suppression determine plant community composition and productivity in desert steppe. Applied Soil Ecology, 168, 104144. doi:https://doi.org/10.1016/j.apsoil.2021.104144

Yang, X., Mariotte, P., Guo, J., Hautier, Y., \& Zhang, T. (2021). Suppression of arbuscular mycorrhizal fungi decreases the temporal stability of community productivity under elevated temperature and nitrogen addition in a temperate meadow. Science of the Total Environment, 762, 143137. doi:https://doi.org/10.1016/j.scitotenv.2020.143137

Yang, X., Shen, Y., Badgery, W. B., Guo, Y., \& Zhang, Y. (2018). Arbuscular mycorrhizal fungi alter plant community composition along a grazing gradient in Inner Mongolia Steppe. Basic and Applied Ecology, 32, 53-65. doi:https://doi.org/10.1016/j.baae.2018.07.002

Yu, H., Ma, Q., Liu, X., Li, Y., Li, L., Qi, M., . . . Zhang, F. (2021). Resistance, recovery, and resilience of desert steppe to precipitation alterations with nitrogen deposition. Journal of Cleaner Production, 317, 128434. doi:https://doi.org/10.1016/j.jclepro.2021.128434

Zhang, T., \& Feng, G. (2021). Arbuscular mycorrhizal fungi alleviate the negative effects of increases in phosphorus $(P)$ resource diversity on plant community structure by improving $\mathbf{P}$ resource utilization. Plant and Soil. doi:10.1007/s11104-020-04825-5

Zhang, W., \& Zhou, T. (2019). Significant Increases in Extreme Precipitation and the Associations with Global Warming over the Global Land Monsoon Regions.Journal of Climate, 32(24), 8465-8488. doi:10.1175/jcli-d-18-0662.1

Zhao, Y., Yang, B., Li, M., Xiao, R., Rao, K., Wang, J., . . . Guo, J. (2019). Community composition, structure and productivity in response to nitrogen and phosphorus additions in a temperate meadow. Science of the Total Environment, 654, 863-871. doi:10.1016/j.scitotenv.2018.11.155

Zheng, Z., Ma, P., Li, J., Ren, L., Bai, W., Tian, Q., . . . Zhang, W.-H. (2018). Arbuscular mycorrhizal fungal communities associated with two dominant species differ in their responses to long-term nitrogen addition in temperate grasslands. Functional Ecology, 32(6), 1575-1588. doi:10.1111/1365-2435.13081

TABLE 1. Analysis of variance for the effects of year $(\mathrm{Y})$, fungicide application $(\mathrm{F})$, nitrogen addition $(\mathrm{N})$ and phosphorus addition $(\mathrm{P})$ on aboveground net primary production (ANPP) and the aboveground biomass of plant species from 2019 to 2020.

\begin{tabular}{lllllll}
\hline & ANPP & ANPP & Stipa breviflora & Stipa breviflora & Agropyron mongolicur \\
\hline Effects & d.f. & $F$ & $P$ & $F$ & $P$ & $F$ \\
Between-subject & Between-subject & & & & & \\
Block & 4,28 & 0.18 & 0.94 & 0.39 & 0.81 & 0.50 \\
F & 1,28 & 0.98 & 0.33 & 0.03 & 0.87 & 0.54 \\
N & 1,28 & $\mathbf{1 3 . 9 8}$ & $<\mathbf{0 . 0 1}$ & 0.26 & 0.62 & 1.43 \\
P & 1,28 & $\mathbf{7 7 . 8 3}$ & $<\mathbf{0 . 0 1}$ & 2.61 & 0.12 & $\mathbf{2 7 . 8 3}$
\end{tabular}




\begin{tabular}{lllllll}
\hline & ANPP & ANPP & Stipa breviflora & Stipa breviflora & Agropyron mongolicur \\
\hline $\mathrm{F} \times \mathrm{N}$ & 1,28 & 0.12 & 0.73 & 0.01 & 0.90 & 1.26 \\
$\mathrm{~F} \times \mathrm{P}$ & 1,28 & 1.93 & 0.18 & 0.15 & 0.70 & 1.11 \\
$\mathrm{~N} \times \mathrm{P}$ & 1,28 & $\mathbf{4 . 6 5}$ & $\mathbf{0 . 0 4}$ & 0.00 & 0.98 & 2.96 \\
$\mathrm{~F} \times \mathrm{N} \times \mathrm{P}$ & 1,28 & 0.09 & 0.77 & 2.29 & 0.14 & 0.13 \\
Within-subject & Within-subject & Within-subject & & & & \\
$\mathrm{Y}$ & 1,28 & 2.70 & 0.11 & 1.44 & 0.24 & $\mathbf{2 7 . 5 7}$ \\
$\mathrm{Y} \times \mathrm{F}$ & 1,28 & 0.03 & 0.85 & 0.01 & 0.92 & 0.14 \\
$\mathrm{Y} \times \mathrm{N}$ & 1,28 & $\mathbf{4 . 7 0}$ & $\mathbf{0 . 0 4}$ & 0.34 & 0.56 & 0.16 \\
$\mathrm{Y} \times \mathrm{P}$ & 1,28 & 2.30 & 0.14 & 0.66 & 0.42 & $\mathbf{2 1 . 4 4}$ \\
$\mathrm{Y} \times \mathrm{F} \times \mathrm{N}$ & 1,28 & 0.02 & 0.89 & 0.29 & 0.60 & 0.92 \\
$\mathrm{Y} \times \mathrm{F} \times \mathrm{P}$ & 1,28 & 0.05 & 0.83 & 0.00 & 0.96 & 0.30 \\
$\mathrm{Y} \times \mathrm{N} \times \mathrm{P}$ & 1,28 & $\mathbf{7 . 4 4}$ & $\mathbf{0 . 0 1}$ & 0.65 & 0.43 & 1.17 \\
$\mathrm{Y} \times \mathrm{F} \times \mathrm{N} \times \mathrm{P}$ & 1,28 & 0.10 & 0.76 & 0.06 & 0.81 & 0.07 \\
\hline
\end{tabular}

Notes : ANPP and the aboveground biomass of plant species all have the same d.f. Bold values are significant at $P<0.05$.
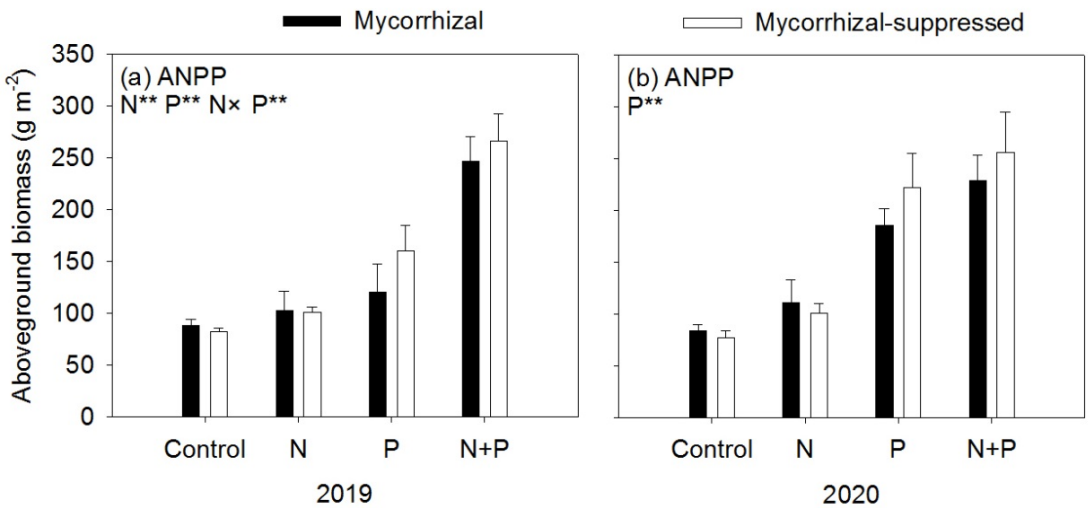

FIGURE 1. Response of above-ground net primary productivity (ANPP) to nitrogen addition (N) and phosphorus addition (P) in mycorrhizal (black bars; non-benomyl addition) and mycorrhizal-suppressed (white bars; benomyl addition) plots in 2019 (a) and 2020 (b). Data are presented as means + SE. ${ }^{*} p<$ $0.05 ;{ }^{* *} p<0.01 ; \mathrm{NS} p>0.05$. 

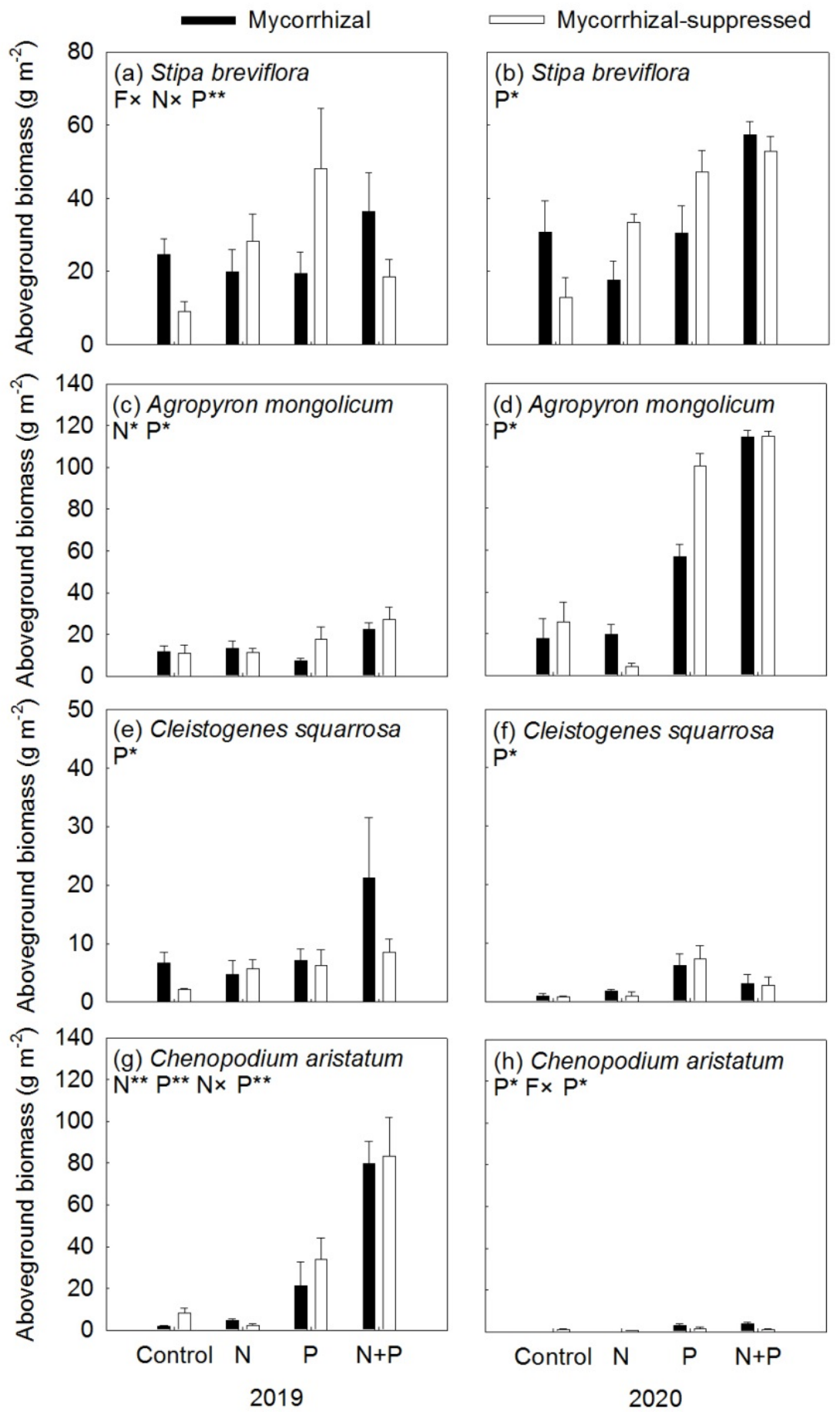

FIGURE 2. Response of aboveground biomass of Stipa breviflora (a, b), Agropyron mongolicum (c, $\mathrm{d})$, Cleistogenes squarrosa (e, f), and Chenopodium album ( $\mathrm{g}, \mathrm{h})$ to nitrogen addition (N) and phosphorus addition $(\mathrm{P})$ in mycorrhizal (black bars; non-benomyl addition) and mycorrhizal-suppressed (white bars; benomyl addition) plots in 2019 (a, c, e and g) and 2020 (b, d f and h). F, fungicide application. Data are presented as means + SE. ${ }^{*} p<0.05 ;{ }^{* *} p<0.01 ; \mathrm{NS} p>0.05$. 


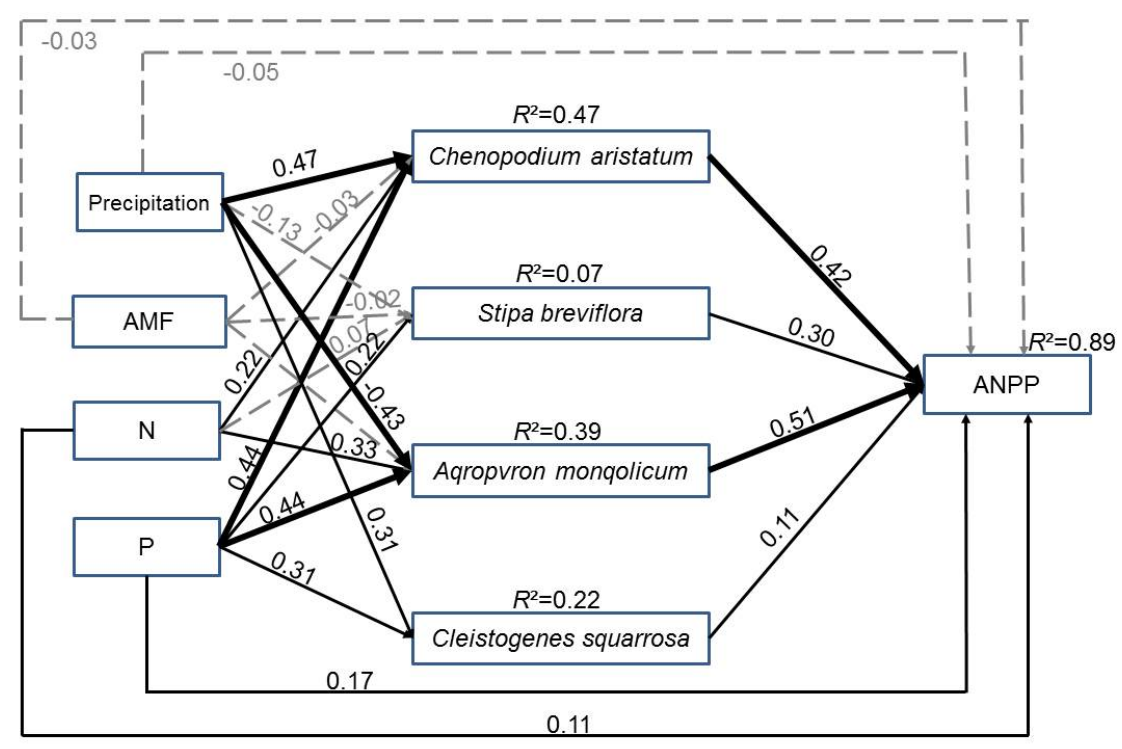

FIGURE 3 . The results of structural equation modelling (SEM) showing the relationship between precipitation, nitrogen addition $(\mathrm{N})$, phosphorous addition $(\mathrm{P})$, arbuscular mycorrhizal fungi (AMF), and dominant species shoot biomass with above-ground net primary productivity (ANPP) across two years. Numbers adjacent to arrows are standardized path coefficients and suggest the effect size of the relationship. The proportion of variance explained $\left(R^{2}\right)$ appears alongside the response variables in the model. Arrows indicate significant (black and solid) and non-significant (gray and dashed) relationships. Goodness-of-fit statistics for each model are shown below the model. $\chi^{2}=15.167, p=0.232$, d.f. $=12$; RMSEA $=0.058, p=0.302$; $\mathrm{AIC}=81.167$. 


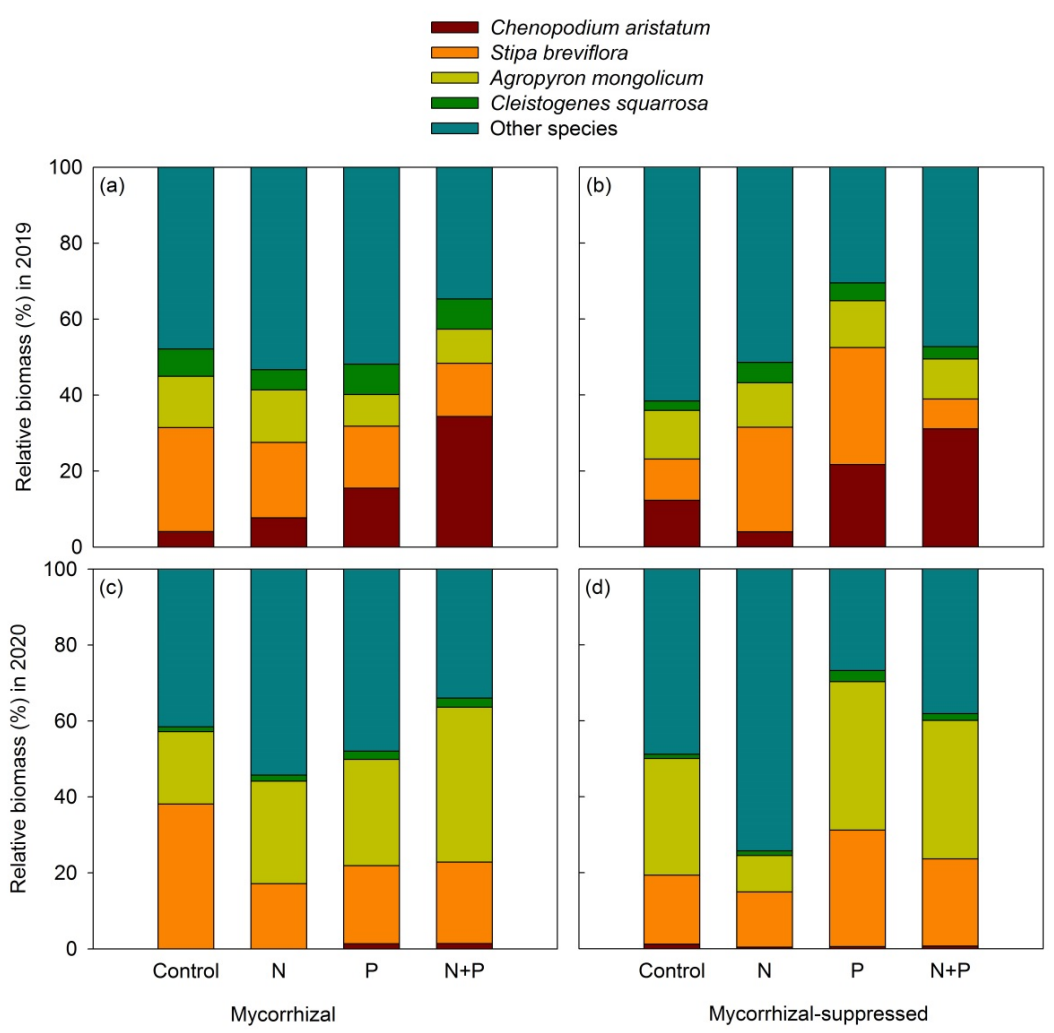

FIGURE 4 . Response of relative shoot biomass of plant species (Stipa breviflora, Agropyron mongolicum ,Cleistogenes squarrosa, Chenopodium aristatum and other species) to nitrogen addition (N) and phosphorus addition $(\mathrm{P})$ in mycorrhizal (black bars; non-benomyl addition) and mycorrhizal-suppressed (white bars; benomyl addition) plots in 2019 (a, b) and 2020 (c, d).
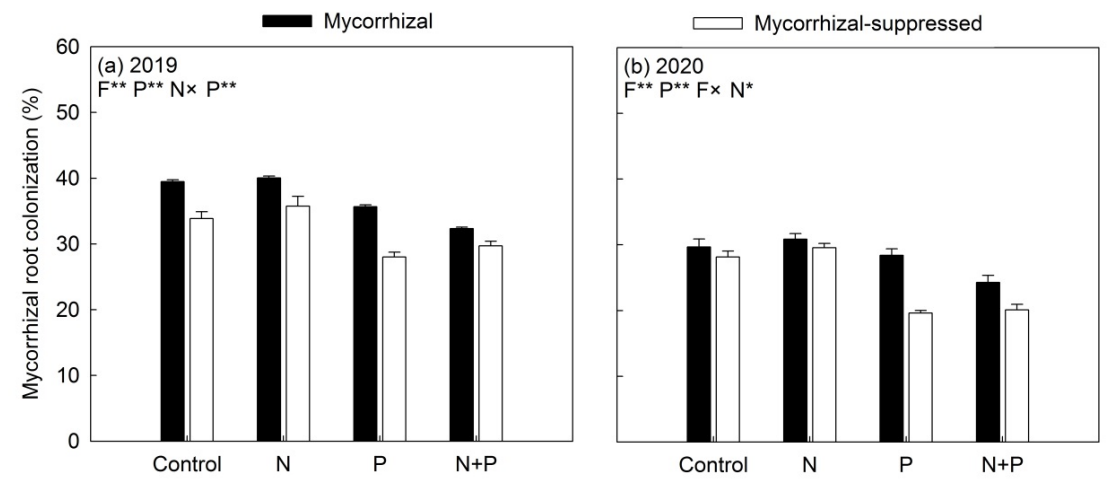

FIGURE 5. Response of mycorrhizal root colonisation (\%) to nitrogen addition (N) and phosphorus addition (P) in mycorrhizal (black bars; non-benomyl addition) and mycorrhizal-suppressed (white bars; benomyl addition) plots in 2019 (a) and 2020 (b). F, fungicide application. Data presented as means + SE. $* * p<0.01 ; \mathrm{NS} p>0.05$. 